\title{
Unilateral Attachment Retained Distal Extension Removable Partial Denture
}

Sravanthi $\mathrm{G}^{1}$, Dinesh BNVK ${ }^{2}$, Taruna $\mathrm{M}^{3}$, Prasad V4

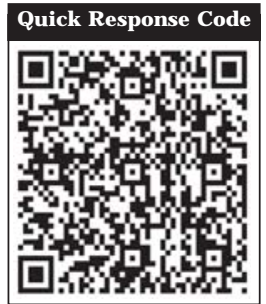

doi: $10.5866 / 2014.641727$

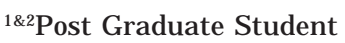

${ }^{3}$ Professor

Department of Prosthodontics

Kamineni Institute of Dental Sciences

Narketpalli, Nalgonda Dist. Telangana

${ }^{4}$ Prof \& HOD

Department of Prosthodontics

Priyadharshini Dental College \& Hospital, Pandur,

Thiruvallur (Dist.) Tamil Nadu.

\section{Article Info:}

Received: J uly 11, 2014

Review Completed: August 10, 2014

Accepted: November 9, 2014

Available Online: J anuary, 2015 (www.nacd.in)

(c) NAD, 2015 - All rights reserved

\section{Email for correspondence:}

gsravanthi0852@gmail.com

\begin{abstract}
:
Attachment retained removable partial denture is not an outdated treatment modality it is even more contemporary in today's appearance oriented society. Attachment retained is a viabl etreatment alternative through which a significant number of patients are benefited. In this case an attachment retained partial denture was chosen as a treatment modality. The purpose of this article is to provide an overview and a simplified approach to this treatment modality by a clinical case report.
\end{abstract}

Key words: Precision Attachment, Extracoronal Attachment, Removable Partial Denture.

\section{INTRODUCTION}

Esthetically and functionally successful prosthetic rehabilitation requires careful attention and meticulous treatment planning. Precision attachments offer considerable advantages in dentistry because of their flexibility. ${ }^{1}$ The use of precision attachments adds a new dimension to dental treatment and also broadens the referral base of a dental surgeon. Successful restoration of the dentition requires plenty of contemporary and conventional treatment techniques and planning and attachment retained partial dentures are one such kind of treatment modality in prosthodontics. ${ }^{2,3}$ Precision attachments could be extracoronal and intracoronal. Intracoronal describes an attachment within the confines of the cusps and normal proximal axial contour or within the normal contours of the crown of a tooth. Extracoronal is that attachment which exists outside, or external to, the crown portion of a natural tooth. The extracoronal attachment projects outside the crown and provides either a rigid or resilient connection between the teeth and the prosthesis. ${ }^{4}$ Attachment-retained cast partial dentures facilitate both esthetic and functional replacement of missing teeth. Studies have shown a survival rate of $83.35 \%$ for 5 years, of $67.3 \%$ up to 15 years, and of $50 \%$ when extrapolated to 20 years. This paper describes a case report of a

\section{Indian Journal of Dental Advancements}

Journal homepage: www. nacd. in 
patient with maxillary unilateral distal extension Kennedy's class II modification II, condition which is prosthetically restored using a unilateral extracoronal castable precision attachment (RHEIN 83 OT attachments system).

\section{CASE REPORT}

A 55-year-old male reported to the department of prosthodontics with chief complaint of missing teeth and wants replacement of those teeth. He gave a history of missing teeth due to an road accident. The patient's medical history revealed no systemic abnormalities. On intraoral examination it was noted that the patient had missing teeth irt 11, 12, $15,16,21,23,31,41,42$ and furcation involvement was seen in relation to 17 (Figurel). The patient's oral hygiene was poor and generalized gingivitis was noted. Radiographic examination was done. Intentional root canal treatment was advised for $22,32,33$, and 43 teeth. Extraction of 17 was done. After complete clinical and radiographic examination, patient is diagnosed of having maxillary Kennedy's class II modification II, and mandibular Kennedy's IV.

\section{Various treatment options available for the patient are:}

- Conventional removable partial denture

- Cast partial denture

- Implant supported prosthesis

- $\quad$ Fixed removable prosthesis.

Upon the various treatment options unilateral precision attachment retained fixed removable prosthesis is planned for the maxilla and porcelain fused metal prosthesis from canine to canine was planned for mandible. Patient exhibited dissatisfaction for removable partial denture and considering his financial problem I mplant supported fixed prosthesis was not planned.

Treatment planning is mainly divided into two phases.

1. Preprosthetic phase

2. Prosthetic phase

\section{Preprosthetic phase includes}

1. Extraction of teeth in relation to $\mathbf{1 7}$

2. Oral prophylaxis

3. Endodontic treatment is done in relation to $22,32,33$, and 43

After pre-prosthetic phase prosthetic treatment plan was set up in the following manner.
Diagnostic impressions were made. Following which diagnostic wax-up was done. A putty matrix was made over the completed diagnostic wax-up for evaluation of the existing space for the extra coronal resilient attachment. The attachment system was selected on the basis of available space. (OT CAP, Rhein 83 Inc, USA).

1) Tooth preparation was done irt 13, 14,22,24, and25 for maxilla and, 32, 33, and 43 for mandible in order to receive PFM crowns (Figure 2).

2) Final I mpression was made in putty and light wash technique and poured in die stone.

3) Following which crowns have been waxed to full contour and milled in wax for obtaining guiding plane surface.

4) The patrices was added to the axial surfaces of the abutment using a dental surveyor (Figure 3).

5) Following which spruing and casting (F igure 4), Metal try in was done for both upper and lower teeth (Figure 5).

6) Finishing and veneering of the fixed component was done.

7) The fixed component including veneer ed metalceramic crowns and the Patrices were tried in the patient mouth and a pick-up impression was made.

8) The matrices of the attachments were placed in the receptacles which were in the crowns on the refractory cast.

9) The wax up of framework of the removable partial denture was done,

10) Investing and casting was done.

11) The framework was evaluated in the patient mouth.

12) J aw relation was done using occlusal rims.

13) Try-in was done

14) And acrylisation of removable partial denture was performed (Figure 6).

15) Cementation of FPD framework was donealong with distal extension removable partial denture retained with unilateral precision attachment; and lower fixed prosthesis cementation was done simultaneously (Figure 7).

Follow up was done every week for one month. Patient was happy and esthetically pleasing with the prosthesis. 


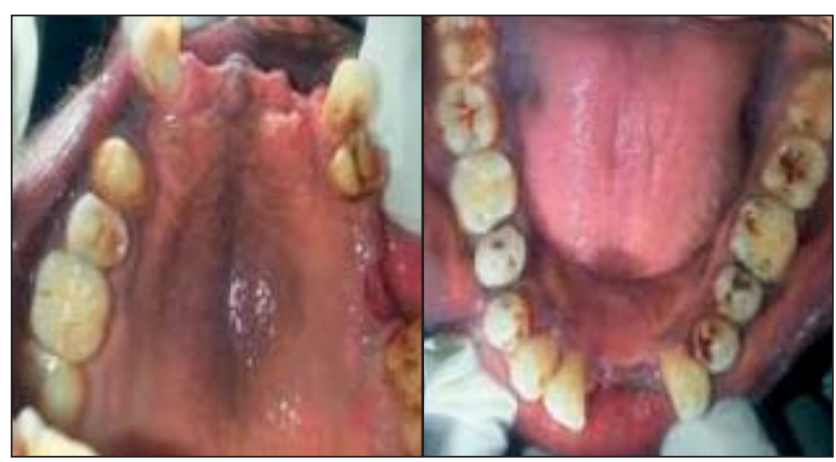

Figure 1: Pre-operative view showing partial edentulism in maxillary and mandibular arches

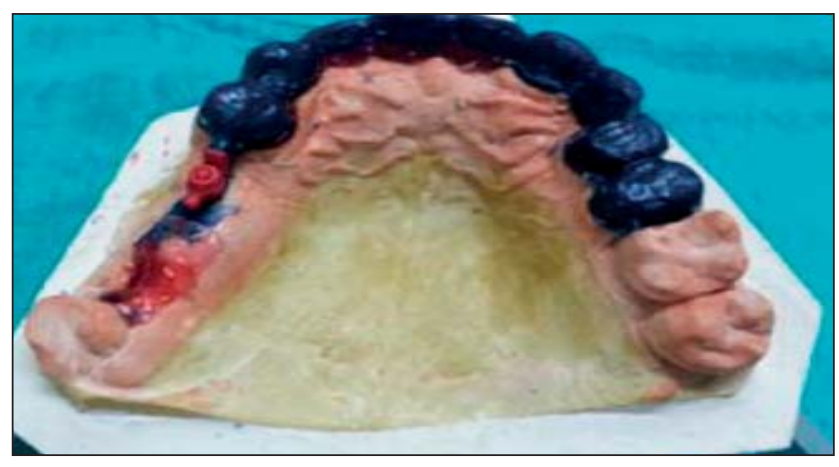

Figure 3: Male component attached to the wax pattern

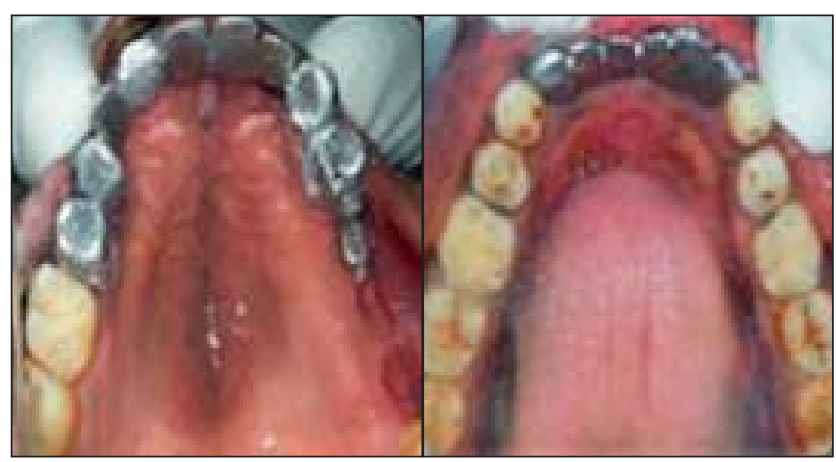

Figure 5: Metal try in

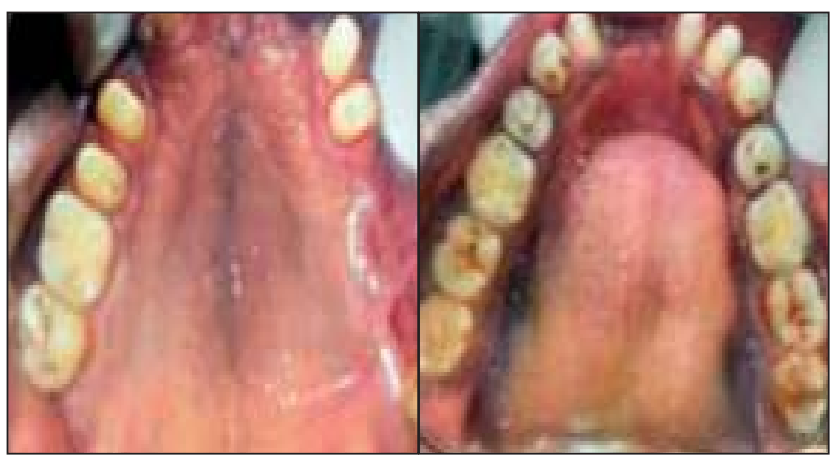

Figure 2: Tooth preparations done in relation to $13,14,22,24,25$ in maxillary arch and 32, 33, 43 in mandibular arch.

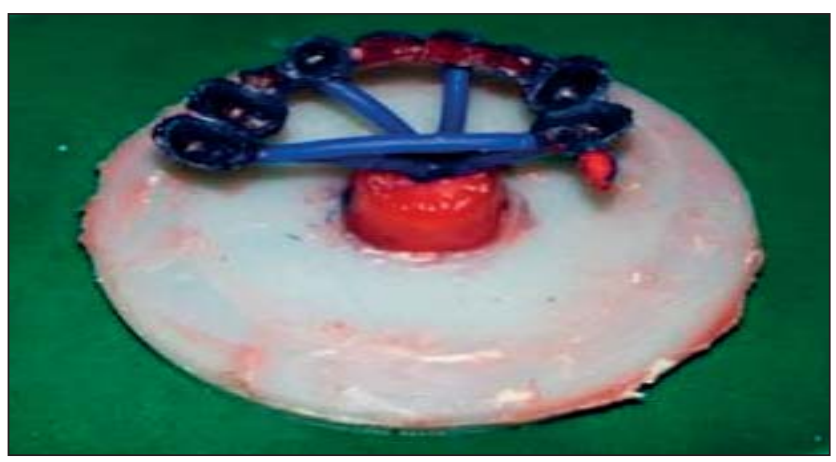

Figure 4: Spruing of the wax pattern

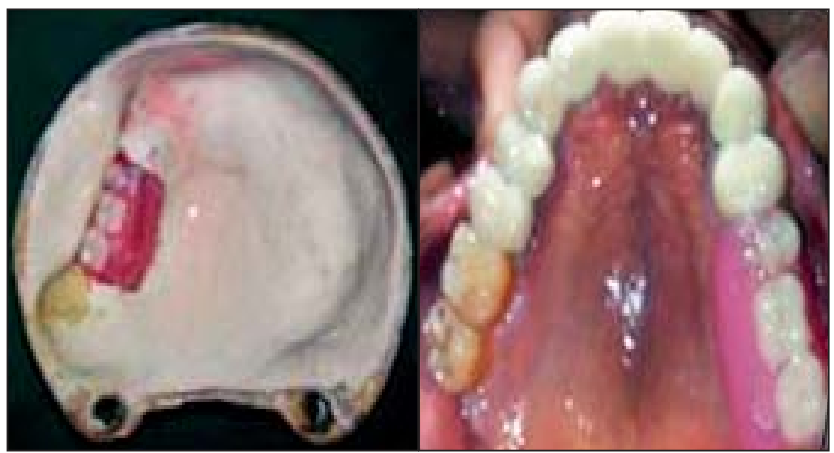

Figure 6: Acrylisation of removable component and final prosthesis

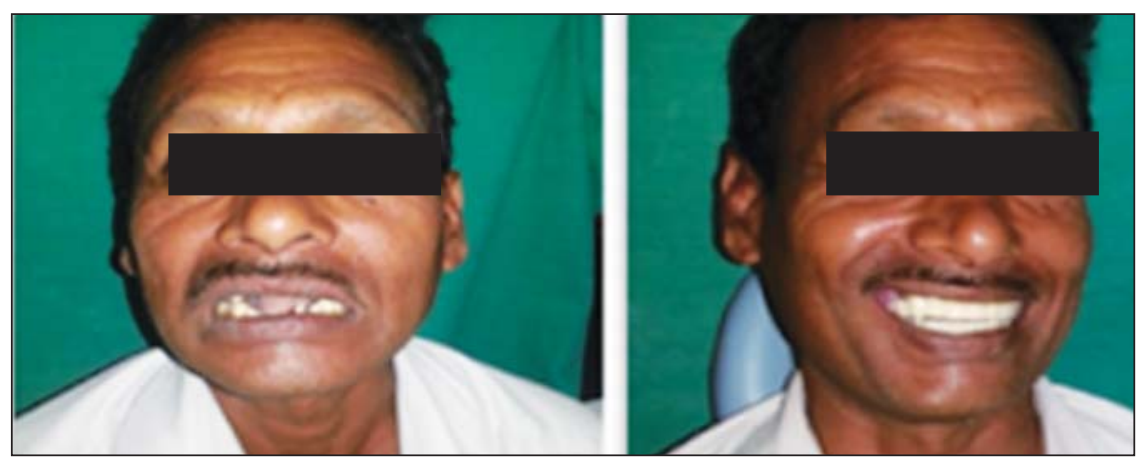

Figure7: Pre operative and Post-operative view 


\section{DISCUSSION}

Despite, a growing trend to use fixed dental prosthesis to maintain more teeth in older agegroups and an increasing use of dental implants, removable dental prosthesis are still prevalent Precision attachment has exceptional feature of being a removable prosthesis with improved aesthetics, less post-operative adjustments and better patient comfort. ${ }^{5,6}$

The overwhelming indication for the attachment RPD is aesthetics. Numerous skillfully designed conventional RPDs are not worn simply because the patient does not like the appearance. Elimination of the buccal or labial direct retainer or clasp arm is a key factor in establishing an esthetically acceptable design.

Contraindications to the use of attachments in RPDs are numerous. Short clinical crowns prove to be the foremost contraindication to the use of attachments in the construction of RPDs. The tooth must have adequate crown height to house the attachment components and effectively offset the leverage forces exerted on the crown. In addition, adequate height must be present for the corresponding attachment components to be housed within the RPD framework or supportive acrylic resin while allowing an optimal artificial tooth placement. ${ }^{5,7}$

They are mostly indicated in long edentulous spans, distal extension bases and non parallel abutments. In this case report abutments were of adequate clinical crown height to receive attachment; multiple abutments were splinted anterior to edentulous span to aid in better distribution of stresses. As the cast partial denture is a fixed removable type, maintenance of the oral hygiene is relatively easy. Added to this the laboratory procedures are simple due to the available preformed prosthetic components and the treatment is economical The support of RPD and its connection with fixed prosthesis generates cross arch stability throughout masticatory activity and permits function similar to that of fixed prosthesis. ${ }^{8,9,10}$ Use of stress attachment system minimizes the metal display improves esthetics. Both extensive fixed dental prosthesis and implantsupported prosthesis can befinancially burdensome to patients since implant supported prosthesis was not considered.

\section{Advantages of attachment retained prosthesis are}

$\checkmark$ Improved comfort and confidence.

$\checkmark$ Enhanced retention, support, and stability.

$\checkmark$ I mproved esthetics as clasps has been eliminated.

$\checkmark$ Preservation of bone.

$\checkmark$ Better distribution of forces and elimination of damaging leverage to natural abutment teeth as splinting of teeth was done.

$\checkmark$ Psychological advantage to patient .

$\checkmark$ An increase in chewing force. Have been achieved for the patient.

\section{Conclusion}

Removable partial dentures fabricated with precision attachments are the viable options for patients in whom fixed prosthesis, implants are contraindicated. Adherence to precision techniques, proper diagnosis treatment plan and periodic recall preventative therapy will result in successful treatment and preservation of the patient's existing dentition.

\section{REFERENCES}

1) Anupama Nigam, Ajay Singh, et al. Precision AttachmentsAn Overview. J Dentofacial Sci 2013; 2(4):41-44.

2) Nitin Bhaskar Shetty, Sanyuktha Shetty et al. Precision Attachments for Aesthetics and Function: A Case Report. J Clin Diagn Res 2014; 8(1):268-270.

3) Summit Makkar,Anuj Chhabra,et al. Attachment Retained Removable Partial Denture: A Case Report Int. J Clin Dent Sci 2011; 2(2):39-43.

4) Edward Feinberg et al. Precision Attachment Case Restoration with Implant Abutments: A Review with Case Reports. J Oral Implant 2011;36(4):489-498.

5) Elliot Feinberg, Edward M Feinberg et al .Attachment retained partial denture. Nys Dent J 1984; 3:161-164.

6) Ashish R J ain, J acob Mathew Philip et al. Attachment retained unilateral distal extension (kennedy's class II modification I cast partial denture). Int J Prostho Res Dent 2012;2(3):101-107.

7) Christopher D. Lynch, Patrick J . Quinn et al. Emergency repair of a fractured dowel-retained precision attachment for a removable partial denture. J Prosthetic Dentistry 2001; 86:320-321.

8) Stanley F. Lorencki et al. Planning precision attachment restoration. J Pros Dent 1969; 21(5):506-509.

9) K. J ayasree, M. Bharathi et al. Precision Attachment: Retained Over denture. J Indian Prosthodont Soc 2012; 12(1):59-62.

10) Modgi Chetan Mukund, Aras Meena Ajay et al. An Innovative Design of 2-Piece Saliva Reservoir Using Precision Attachment: A Case Report. J Indian Prosthodont Soc 2012; 12(4):260-263. 